\title{
CALCULATION OF FRACTURE MECHANIC PARAMETERS VIA FEM FOR SOME CRACKED PLATES UNDER DIFFERENT LOADS
}

\author{
Ngo Huong Nhu and Nguyen Truong Giang \\ Institute of Mechanics, VAST, 264 Doi Can, Hanoi, Vietnam
}

\begin{abstract}
This paper describes some results in analyzing cracked plates via FEM based on the procedures in CASTEM 2000 [1]. The basic methods for computing the crack parameters by the finite element analysis are presented. Some programs written by GIBIAN languages to solve problems for cracked plates are given. In possible cases, the numerical results are composed with analytical solution or testing result that gives a good agreement. The influence of plate configurations, the crack length, the external load type on the crack characteristic values are considered. The numerical analysis for inclined crack at angle and in arbitrary position of plate, the crack at hole in the plate, the crack of gravity dams are realized. The given results and programs can be applied to practical problems for controling the brittle failure state of a structure.
\end{abstract}

\section{THE MAIN METHODS FOR CALCULATION OF FRACTURE MECHANIC PARAMETERS VIA FEM}

The determination of fracture mechanics parameters as Stress Intensity Factors (SIF), energy release rate $G, J$ - integral Rice and Crack Opening Displacement (COD) plays an important role in fracture analysis. By comparing these parameters with critical values one can estimate the brittle failure state of structures. Nowaday, the crack analysis is founded on three different following methods.

\subsection{Estimation of stress intensity factors by extrapolation of displacements or stresses}

The stress intensity factors (SIF) $K_{I}$ can be defined as a function of $r$ [2]:

$$
K_{I}=\frac{2 \mu}{(\chi+1)} \sqrt{\frac{2 \pi}{r}} v(\theta=\pi),
$$

where $v(\theta)$ is Westergard displacement solution:

$$
\begin{aligned}
& v(\theta)=\frac{K_{I}}{8 \mu} \sqrt{\frac{2 r}{\pi}}\left((2 \chi+1) \sin \frac{\theta}{2}-\sin \frac{3 \theta}{2}\right)+\frac{K_{I I}}{8 \pi} \sqrt{\frac{2 r}{\pi}}\left((2 \chi-3) \cos \frac{\theta}{2}+\cos \frac{3 \theta}{2}\right) \\
& \chi=\frac{3-\nu}{1+\nu} .
\end{aligned}
$$

In FEM the function $\mathrm{K}_{I}(\mathrm{r}), \mathrm{K}_{I I}(\mathrm{r})$ are defined from displacements $v(\theta=\pi)$ or $v(\theta=0)$ at the nodes nearest to the crack tip. The values $\mathrm{K}_{I}, \mathrm{~K}_{I I}$ are given by extrapolation $\mathrm{K}_{I}(r)$, $\mathrm{K}_{I I}(\mathrm{r})$ for points $r$ near to 0 (Fig. 1). 
Note that the stress intensity factors can be also defined from Westergard stresses solutions. The failure occurs when $\mathrm{K}_{I}=\mathrm{K}_{I C}$, where $\mathrm{K}_{I C}$ is a measure of the critical material toughness.

In the Castem 2000 procedure SIF is based on the above mentioned method. It allows to calculate the stress intensity factors $K_{I}, K_{I I}$ from displacements (1.1) of the sides of the crack. The values $\mathrm{K}_{I}, \mathrm{~K}_{I I}$ are a mean of the displacements of three points, which are closest to the crack tip.

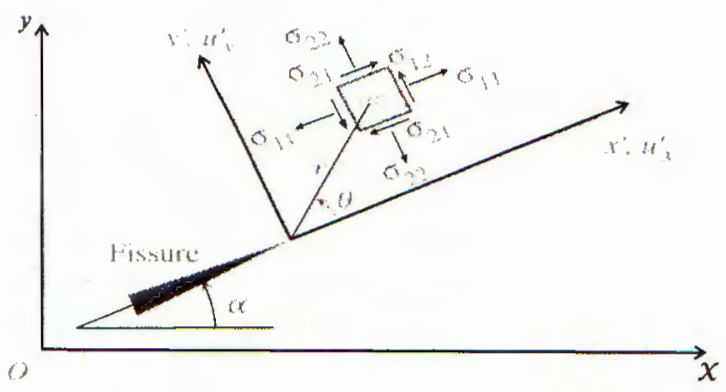

Fig. 1. The stress field near the tip of a crack

\subsection{Calculation of the energy release rate $G$}

The energy release rate $G$ in the two-dimension body with unit thickness is evaluated by ratio of variation of energy potential and fissure length [2]:

$$
G=-\frac{\partial W_{p o t}}{\partial a}=-\frac{W_{p o t}(a+\Delta a)-W_{p o t}(a)}{\Delta a}
$$

where:

$$
\begin{gathered}
W_{\text {pot }}=W(\varepsilon)-W_{\text {ext }}=\int_{\Omega} w(\varepsilon) d \Omega-\int_{\Sigma_{F}} T_{i} u_{i} d \Sigma_{F}-\text { the energy potential } \\
\int_{\Omega} w(\varepsilon) d \Omega \text { - strain potential, } \int_{\Sigma_{F}} T_{i} u_{i} d \Sigma_{F}-\text { external force work. }
\end{gathered}
$$

The energy potential may be received from FEM formulas:

$$
W_{\text {pot }}=\sum_{i=1}^{n}\left\{u_{i}\right\}^{t} K_{i}\left\{u_{i}\right\}-\left\{u_{i}\right\}^{t}\{R\} .
$$

The displacement $u_{i}$, deformation and stress fields are evaluated by FEM, $\{\mathrm{R}\}$ is nodal vector and the energy $W_{\text {pot }}$ is calculated for two problems with fissures $a$ and $a+\Delta a$.

At fracture $G=G c, G c$ is material resistant to fracture, defined by combination of critical stress and crack size for failure [3].

\subsection{Calculation of the $J$ integral}

The stress- strain field at the tip of a crack can be characterizied by $J$ - integral Rice. The $J$ - integral is identical to $G$ for linear elastic behavior and it can be received from 
(1.2) for a fissure with the length of $a$ on the axis $O x[2]$ :

$$
J=\int_{\Sigma_{F}}\left[w(\varepsilon) d y+T_{i} \frac{\partial u_{i}}{\partial x} d \Sigma_{F}\right]
$$

where $\Sigma_{F}$ is a any contour surrounding the crack tip, which goes from lower crack side to its upper, $w$ is the strain energy density, $T_{i}$ is a traction vector in the outward normal along $\Sigma_{F}, u_{i}$ is a displacement and $d \Sigma_{F}$ is an element of the arc length along $\Sigma_{F}$.

All displacement, deformation and stress values for calculating $J$-integral are obtained from analyzing by FEM. The numerical integration (1.3) is calculated in each side of element by Gauss method and the integration takes place within one layer of elements around crack tip. Procedure $G$ - theta in Castem 2000 is realized in this basis. It let to calculate $\mathrm{G}$ and $J$ for elastic and inelastic behaviour. Operator COD let to calculate Crack Opening Displacement from the displacement values on the crack side.

For mixed mode $I$ and $I I, G$ and $J$ can be received from stress intensity factors $\mathrm{K}_{I}$ and $K_{I I}$ by [3]:

$$
G=J=\frac{K_{I}^{2}+K_{I I}^{2}}{E^{\prime}}
$$

where $E^{\prime}=E$ - for the plane stress state, $E^{\prime}=\frac{E}{1-\nu^{2}}$ - for the plane strain state.

\section{NUMERICAL SIMULATION AND CALCULATING OF FRACTURE MECHANICS PARAMETERS FOR SOME CRACKED PLATES}

In this part some results of calculating fracture mechanics parameters of plates with fissures are presented. To obtain them, some programs are written by languages Gibian by using operators of FEM, procedures SIF and $G$ - theta in the Castem 2000 to modelize different positions of crack in the plates and to solve the crack plate problems with the different geometry and type of loading. These programs can estimate the Stress Intensity Factor $\mathrm{K}_{I}, \mathrm{~K}_{I I}$, the energy release rate $G$, the displacement of the crack tip $U x$, and Crack Opening Displacement COD for many problems. They are followings:

- Program RUPSB for a center crack plates in a tension.

- Program RUPTIN for plates with the inclined crack at angle $\beta$ from $0 x$ for axial and biaxial loading.

- Program RUPHOL for crack at hole in the plate under biaxial loading.

- RUPDAM for crack gravity dam under hydrostatic loading and its own weight.

The general steps for all programs are:

- Input all material, geometrical characteristics, boundary and loading conditions for FEM analysis of plate.

- The crack points, the length of crack tips, the crack position and sides of crack will be input data.

- Meshing the structures and its fissure. The local FE mesh must be refined in the surrounding or front of crack tips by special technique for each problem.

- Using operators SOLV for linear problem and procedure PASAPAS for nonlinear problem to give corresponding displacement and stress fields.

- Application of the procedures SIF or $G$ - theta or COD requires following input data: 
+ The field of material properties

+ The displacement field

+ The crack points, the line describing the side of the crack (mesh),

The second side of crack for loading in mix mode or inclined crack.

- Indicate the outputs for example: Stress Intensity Factors in interested point, the energy release rate $G$, the Rice - integral for a plates and Crack Opening Displacement at any point in the crack side.

So, all these codes request not only the informations for a Fine Element Method but also the crack situation. These received codes let automatically to mesh for local zone of crack tips and whole structures with indicated density.

\subsection{The solutions for a center cracked plate in a tension}

2.1.1 The polynomial expression for a finite plate with center crack under tensile stress [3]

$$
K_{1}=\sigma \sqrt{\pi a}\left[\sec \left(\frac{\pi a}{2 w}\right)\right]^{\frac{1}{2}}\left[1-0.025\left(\frac{a}{w}\right)^{2}+0.06\left(\frac{a}{w}\right)^{4}\right]
$$

$2 w$ is a width of the plate, $2 a$ is a length of the fissure, $\sigma$ is a tensile stress.

\subsubsection{The numerical solutions $K_{I}$ for cracked plates with different ratios a/w}

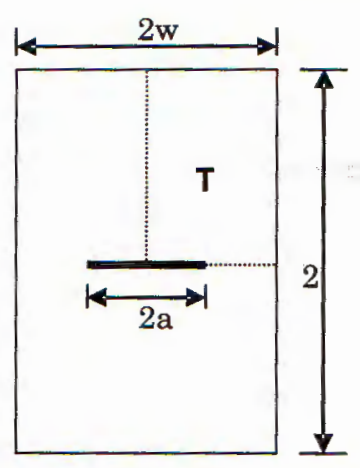

Fig. 1a. Modeling of the plate $a=100 \mathrm{~mm}, w=200 \mathrm{~mm}$

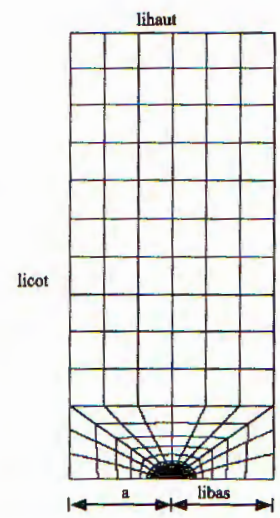

Fig. 1b. The model of the quater crack plate $a=100 \mathrm{~mm}, b=200 \mathrm{~mm}$

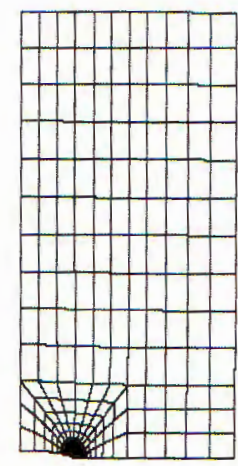

Fig. 1c. The deformation of the crack plate $a=100 \mathrm{~mm}, w=400 \mathrm{~mm}$

Consider a cracked plate subjected to a tensile stress $\sigma=10 \mathrm{Mpa}$ (Fig. 1a). The width and length of this plate are $2 w$ and $2 h$ with $w=200 \mathrm{~mm} ; h=600 \mathrm{~mm}$. The crack is located at the middle of plate and the length of the fissure is $2 a, a=100 \mathrm{~mm}$. The plate is made from brittle material with $E=20000 \mathrm{MPa}, \nu=0.3$.

The geometry shape and loading of plate are symmetrically, therefore one considers only $^{1 / 4}$ of the plate, which is divided for example into 248 elements and 675 nodes (for $a / w=1 / 2$, Fig. 1b) and 313 elements, 880 nodes (for $a / w=1 / 4$, Fig. 1c). The condition of symmetry is modelized as following: on the line licot displacements $U x=0$ and $U y=0$ on the line libas. 
Using RUPTS to analyze other plates with different values of ratio of crack length and width $a / w$. The calculated results are compared with solution (2.1) and are shown in the Table 1. The units of Stress intensity Factors $\mathrm{K}_{I}$ and $\mathrm{K}_{I I}$ in all tables in this work is $\left(\mathrm{MPA} \cdot \mathrm{mm}^{0.5}\right), G(\mathrm{MPA} . \mathrm{mm}), 1 \mathrm{MPa}=1 \mathrm{~N} / \mathrm{mm}^{2}$.

Table 1. The calculated results of center cracked plates with $a=100(\mathrm{~mm}), w=200,300,400,500(\mathrm{~mm}), \mathrm{h}=600 \mathrm{~mm}$

\begin{tabular}{|c|c|c|c|c|c|c|c|c|}
\hline $\mathrm{a} / \mathrm{w}$ & $\begin{array}{c}\mathrm{Ux} \\
(\mathrm{mm})\end{array}$ & $\begin{array}{c}\mathrm{COD} \\
(\mathrm{mm})\end{array}$ & $\begin{array}{c}\mathrm{K}_{I} \\
(\mathrm{SIF})\end{array}$ & $\begin{array}{c}\mathrm{K}_{I} \\
(\text { theory })\end{array}$ & $\begin{array}{c}\text { Err } \\
\%\end{array}$ & $\mathrm{G}$ & $\begin{array}{c}\mathrm{K}_{I} \\
(\mathrm{G}-\text { Theta })\end{array}$ & $\begin{array}{c}\text { Err } \\
\%\end{array}$ \\
\hline $1 / 2$ & -0.05397 & 0.107372 & 208.60 & 210.25 & -0.794 & 2.0105 & 210.21 & 0.022 \\
\hline $1 / 3$ & -0.04831 & 0.097504 & 188.73 & 190.07 & -0.714 & 1.6453 & 190.16 & 0.045 \\
\hline $1 / 4$ & -0.04707 & 0.095050 & 183.81 & 184.16 & -0.190 & 1.5606 & 185.20 & 0.561 \\
\hline $1 / 5$ & -0.04690 & 0.094550 & 182.77 & 181.58 & 0.650 & 1.5430 & 184.16 & 1.395 \\
\hline
\end{tabular}

The results in the Table 1 show that:

- The calculated results for the $\mathrm{K}_{I}$ by RUPSB with both SIF and $G$ - Theta procedures have a good agreement with analytical results (2.1) for all symmetrical center cracked plates in tension.

- When the width $w$ of a plate (or loading boundary side) more increases but the crack length isn't change, the stress intensity factor $\mathrm{K}_{I}$, the energy release rate $G$, displacement of the crack tip $U x$, and Crack opening displacement COD more decrease.

\subsubsection{The numerical solutions $K_{I}$ for cracked plates with different ratios $a / h$}

The numerical results in the Table 2 show that the height of finite plate has a litlle influence on the $\mathrm{K}_{I}$ as $a / h \leq 1 / 2$. The solution (2.1) with all different $h$ is: $\mathrm{K}_{I}$ (theory) $=210.25$ (MPA.mm ${ }^{0.5}$ ) is compared with numerical solutions as following:

Table 2. The calculated results of center cracked plates with different $h$ $a=100(\mathrm{~mm}), w=200(\mathrm{~mm}), h=200,400,600,800(\mathrm{~mm})$

\begin{tabular}{|c|c|c|c|c|c|}
\hline $\mathrm{h}(\mathrm{mm})$ & $\mathrm{h} / \mathrm{a}$ & $\mathrm{Ux}(\mathrm{mm})$ & $\mathrm{COD}(\mathrm{mm})$ & $\mathrm{K}_{I}($ Cal. $)$ & Err \% \\
\hline 200 & $1 / 2$ & -0.06613 & 0.12627 & 234.83 & 10.46 \\
\hline 400 & $1 / 4$ & -0.05415 & 0.10751 & 208.77 & -0.711 \\
\hline 600 & $1 / 6$ & -0.05399 & 0.10737 & 208.60 & -0.794 \\
\hline 800 & $1 / 8$ & -0.05399 & 0.10737 & 208.60 & -0.795 \\
\hline
\end{tabular}

In next part the unsymmetrical cracked plates will be considered.

\subsection{The solutions for plates with the inclined crack}

Consider plates with the inclined crack subjected to uniaxial and biaxial loading. The numerical results for some plates with different angles $\beta$ and any position of crack are received by application RUPIN. The calculated results are checked with the theoretical results of SIF. 
2.2.1 The analytical expression of the stress intensity factors for infinite plate when a crack is oriented $\left(90^{\circ}-\beta\right)$ degrees from the applied normal stress [3]

For uniaxial loading:

$$
\begin{aligned}
& K_{I}=K_{I(0)} \cos ^{2}(\beta), \\
& K_{I I}=K_{I(0)} \sin (\beta) \cos (\beta),
\end{aligned}
$$

where $\mathrm{K}_{I(0)}$ is the Mode I Stress Intensity when $\beta=0$. For finite plate $\mathrm{K}_{I(0)}$ are taken as the same as (2.1). The maximum $\mathrm{K}_{I I}$ occurs at $\beta=45^{\circ}$, where the shear stress is also at a maximum.

For biaxial loading:

$$
\begin{gathered}
K_{I}=K_{I(0)}\left(\cos ^{2}(\beta)+B \sin ^{2}(\beta)\right), \\
K_{I I}=K_{I(0)}(\sin (\beta) \cos (\beta))(1-B),
\end{gathered}
$$

where $\mathrm{B}=\sigma_{1} / \sigma_{2}$, tension stresses on the directions $O y$ and $O x$ and $\sigma_{1}>\sigma_{2}$.

\subsubsection{The numerical solutions for rectangular plates with an inclined crack}

\section{For uniaxial loading}

Consider the problem for a plate subjected to tensile stress $\sigma=10 \mathrm{Mpa}, a=100$ $\mathrm{mm}, w=200 \mathrm{~mm}, E=20000 \mathrm{MPa}, \nu=0.3$, the crack $a=100 \mathrm{~mm}$ is inclined at an angle $\left(90^{\circ}-\beta\right)=45^{\circ}$ to the direction of extension. Using RUPTI, the plate with two crack tips is divided into 905 elements with 2409 nodes (Fig. 2). Near to the crack tip zones the meshes have a small density. The boundary conditions are: $U y=0$ at the point $P_{0} ; \dot{U} x=0$ at the points $P_{4}$ and $A P_{4}$. With different angles $\beta=0 ; 20 ; 30 ; 45$ degrees, the results are compared with analytical solution $(2.2)$ in the Table 3 . The error is estimated as:

The error $\%=\left[\left(\mathrm{C}_{\text {alculated }} \mathrm{K}_{\text {theory }}\right) / \mathrm{C}_{\text {alculated }}\right]^{*} 100 \%$.

Table 3. The calculated SIF for inclined crack in a plate with uniaxial loading and different angles $\beta$

\begin{tabular}{|c|c|c|c|c|c|c|c|c|}
\hline$\beta^{0}$ & $\begin{array}{c}\mathrm{Ux} \\
(\mathrm{mm})\end{array}$ & $\begin{array}{c}\mathrm{COD} \\
(\mathrm{mm})\end{array}$ & $\begin{array}{c}\mathrm{K}_{I} \\
\text { (calcul.) }\end{array}$ & $\begin{array}{c}\mathrm{K}_{I} \\
\text { (theory) }\end{array}$ & $\begin{array}{c}\mathrm{Err} \\
\%\end{array}$ & $\begin{array}{c}\mathrm{K}_{I I} \\
\text { (Calcul.) }\end{array}$ & $\begin{array}{c}\mathrm{K}_{I I} \\
\text { (Theory) }\end{array}$ & $\begin{array}{c}\text { Err } \\
\%\end{array}$ \\
\hline 0 & -0.0532 & 0.1072 & 207.15 & 210.25 & -1.49 & - & - & - \\
\hline 20 & -0.0517 & 0.1054 & 184.41 & 185.66 & -0.67 & 57.935 & 67.573 & -16.64 \\
\hline 30 & -0.0494 & 0.0982 & 158.16 & 157.69 & 0.29 & 80.097 & 91.041 & -13.6 \\
\hline 45 & -0.0428 & 0.0809 & 107.15 & 105.13 & 1.89 & 95.632 & 105.13 & -9.926 \\
\hline
\end{tabular}

\section{For biaxial Loading}

Consider above cracked plate $w=200 \mathrm{~mm}, h=600 \mathrm{~mm}$ subjected to principal stresses $\sigma_{1}=20 \mathrm{MPa}$ and $\sigma_{2}=10 \mathrm{MPa}$ and $B=\sigma_{1} / \sigma_{2}=2, \sigma_{1}>\sigma_{2}$. The calculated results are shown in the Table 4 are compared with theoretical stress intensity factors (2.3) for different angles. 


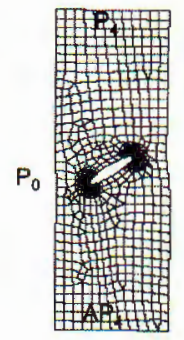

Fig. 2a. The deformation of the plate with $w=200, h=600, \beta=30^{\circ}$

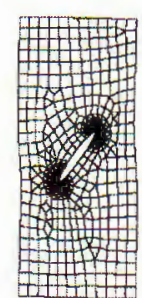

Fig. 2b. The deformation of the plate with $w=200, h=400, \beta=45^{0}$

Table 4. The calculated $K_{I}, K_{I I}$ for different angles $\beta$ for biaxial loading

\begin{tabular}{|c|c|c|c|c|c|c|c|c|}
\hline$\beta^{0}$ & $\begin{array}{c}\mathrm{Ux} \\
(\mathrm{mm})\end{array}$ & $\begin{array}{c}\mathrm{COD} \\
(\mathrm{mm})\end{array}$ & $\begin{array}{c}\mathrm{K}_{I} \\
\text { (calcul.) }\end{array}$ & $\begin{array}{c}\mathrm{K}_{I} \\
\text { (theory) }\end{array}$ & $\begin{array}{c}\text { Err } \\
\%\end{array}$ & $\begin{array}{c}\mathrm{K}_{I I} \\
\text { (calcul.) }\end{array}$ & $\begin{array}{c}\mathrm{K}_{I I} \\
\text { (theory) }\end{array}$ & $\begin{array}{c}\text { Err } \\
\%\end{array}$ \\
\hline 0 & -0.0610 & 0.2145 & 414.30 & 420.5 & -1.49 & - & - & - \\
\hline 30 & -0.0629 & 0.2045 & 376.03 & 36794 & 2.15 & 68.039 & 91.041 & -33.6 \\
\hline 45 & -0.059 & 0.1714 & 330.71 & 315.38 & 4.63 & 88.50 & 105.13 & -19.39 \\
\hline 60 & -0.0472 & 0.1235 & 279.06 & 262.81 & 5.82 & 83.030 & 91.041 & -9.647 \\
\hline 75 & -0.0264 & 0.0648 & 236.21 & 224.33 & 5.02 & 48.433 & 52.563 & -8.52 \\
\hline
\end{tabular}

Remarks:

- The written code RUPTIN for the plates with inclined crack with two crack tips gives a high precision for $\mathrm{K}_{I}$ in the all loading cases. The accuracy for $K_{I I}$ can be accepted for angle $\beta$ greater than 45 degree.

- The values of $\mathrm{COD}, U x, \mathrm{~K}_{I}$ decrease when $\beta$ increase. When $\beta=45^{\circ}$, the calculated value of $\mathrm{K}_{I I}$ gets a maximum as the same as in the theory.

- In the uniaxial case, when $\beta=0$ the result $\mathrm{K}_{I}=207.15$ (Table 3 ) is closed to $\mathrm{K}_{I}=$ 208.60 (Table 1) so the written programs give a good agreement.

\subsection{The plate has an interior inclined crack in arbitrary position}

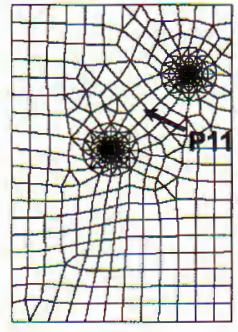

Fig. 3a. The mesh of plate $w=400 \mathrm{~mm}$, $h=600 \mathrm{~mm}, a=200 \mathrm{~mm}, \beta=45^{\circ}$

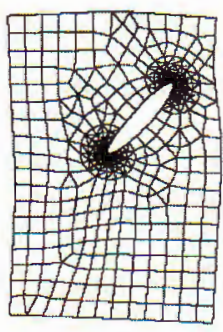

Fig. 3b. The cracked plate after deformation

The RUPTIN also can solve problems for crack in arbitrary position of the plate.

Consider two cases of the cracked plate (Fig. 3) with $w=400 \mathrm{~mm}, h=600 \mathrm{~mm}$, when the length of the crack $2 a$ is: $a=200 \mathrm{~mm}$ and $a=100 \mathrm{~mm}$. The middle point of a crack (point $P 11$ ) has arbitrary coordinates $(x, y)$, for example $x=500 \mathrm{~mm}, y=200 \mathrm{~mm}$. The angle of the crack is inclined at $45^{\circ}$ to $O x$. The material and biaxial loading characteristics 
are the same as the previous problem. The deformation of this plate is shown in the Fig. $3 \mathrm{~b}$. The boundary conditions are the same as in the above case 2 . The crack characteristics of this plate are shown in Table 5, where these values are given for a one crack tip PF, for other crack tip they can be easy received.

Table 5. The crack characteristics of the plate with inclined crack with the different crack length or angles

\begin{tabular}{|c|c|c|c|c|}
\hline $\mathrm{a}(\mathrm{mm}), \beta$ & $\mathrm{K}_{I}$ & $\mathrm{~K}_{I I}$ & $\mathrm{COD}$ & $\mathrm{Ux}$ \\
\hline $\begin{array}{c}\mathrm{a}=100, \beta=45^{\circ} \\
(\mathrm{EL}: 1400, \text { Nodes: } 3910)\end{array}$ & 287.32 & 91.029 & 0.27767 & -0.00309 \\
\hline $\begin{array}{c}a=200, \beta=45^{\circ} \\
(\mathrm{EL}: 678, \text { Nodes: } 1688)\end{array}$ & 532.09 & 157.89 & 0.46981 & 0.01777 \\
\hline $\begin{array}{c}\mathrm{a}=200, \beta=30^{\circ} \\
(\mathrm{EL}: 682, \text { Nodes: } 1700)\end{array}$ & 627.45 & 117.25 & 0.56232 & 0.00893 \\
\hline
\end{tabular}

Note that when the length of the crack increases, all crack characteristics increase, when the angle of the crack decreases $\mathrm{K}_{I}$, COD increase too. So the RUPTIN can be apply for any plate with any interior inclined crack of different values $a, w, h, \beta, x$ and $y$.

\subsection{The problem for the crack at hole in the plate}

The examples in this part show capabilities of the RUPHOL for problems with complicated geometry. Consider a rectangular plate with $2 w=250 \mathrm{~mm}$ and $2 h=200 \mathrm{~mm}, E=$ $20000 \mathrm{MPa}, \nu=0.3$. The plate has a hole with radius $R=30 \mathrm{~mm}$ and center at $C(x, y)$ (Fig. 4). The crack is point lies at the hole at point $\mathrm{P} 11(x=100 \mathrm{~mm}, y=0 \mathrm{~mm})$. The length of crack $\mathrm{a}=50 \mathrm{~mm}$. The crack inclined at angle $\beta$ to the axis $O x$. The plate is subjected to tension stresses on opposite sides LG and LD with $\sigma=-10 \mathrm{~N} / \mathrm{mm}^{2}$. The boundary conditions are: at P0: $U x=0, U y=01$; at $P 2: U y=0$. The influence of the hole position, the crack point position on the crack characteristic parameters are considered with different $C(x, y), \mathrm{P} 11(\mathrm{x}, \mathrm{y})$.

\subsubsection{The hole is not posited in the middle of plate with different angles $\beta$}

In the case when the center of the hole $C(100,-30), \mathrm{P} 11(x=100 \mathrm{~mm}, y=0 \mathrm{~mm})$ (Fig. 4), the results by application of program RUPHOL give:

Table 6 . The calculated results for the crack at hole in the plate with different angles $\beta$

\begin{tabular}{|c|c|c|c|c|}
\hline$\beta$ & $\mathrm{K}_{I}$ & $\mathrm{~K}_{I I}$ & $\mathrm{COD}(\mathrm{mm})$ & $\mathrm{Ux}(\mathrm{mm})$ \\
\hline $30^{0}$ & 51.964 & -93.994 & $-1.84846 .10^{-2}$ & $7.38299 .10^{-2}$ \\
\hline $45^{0}$ & 100.93 & -95.166 & $-1.95199 .10^{-2}$ & $6.24685 .10^{-2}$ \\
\hline $60^{0}$ & 147.11 & -78.690 & $-2.46177 .10^{-2}$ & $5.60088 .10^{-2}$ \\
\hline
\end{tabular}

The shape of the crack after deformation is shown in the Fig. $4 \mathrm{~b}$. 


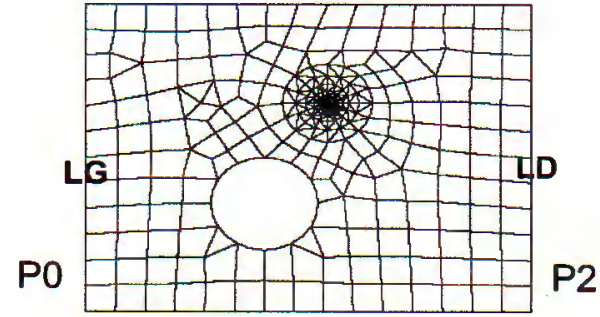

Fig. 4a. The mesh of plate with crack at hole when $\beta=45^{\circ}, C(100,-30)$

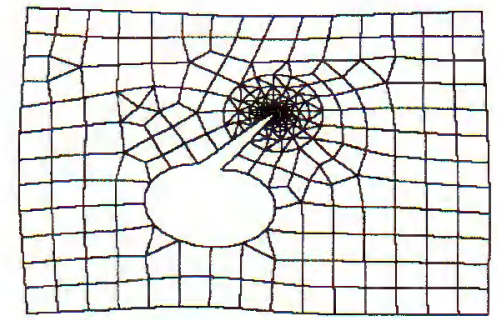

Fig. 4b. The deformation of the plate with crack at hole

\subsubsection{The hole is posited in the different places}

To estimate the influence of positions of the hole on the results of crack analysis, the problems are solved for different centers of hole $C(x, y)$ with the highest point of crack $P 11(125,30)$ on the hole. The crack inclined at angle $\beta=45^{\circ}$ to the axis $O x$. The results of crack analysis by RUPHOL are presented in the Table 7 .

Table \%. The crack characteristics for the crack at hole with different center $C(x, y)$

\begin{tabular}{|c|c|c|c|c|c|}
\hline $\mathrm{C}(\mathrm{x}, \mathrm{y})$ & $\mathrm{K}_{I}$ & $\mathrm{~K}_{I I}$ & $\mathrm{COD}(\mathrm{mm})$ & $\mathrm{Ux}(\mathrm{mm})$ & $\mathrm{J}$ or $\mathrm{G}$ \\
\hline$(100,-30)$ & 100.93 & -95.166 & $-1.95199 .10^{-2}$ & $6.24685 \cdot 10^{-2}$ & $8.80967 \cdot 10^{-1}$ \\
\hline$(110,-20)$ & 98.596 & -95.728 & $-1.73148 \cdot 10^{-2}$ & $6.09693 \cdot 10^{-2}$ & $8.6510 \cdot 10^{-1}$ \\
\hline$(110,-10)$ & 98.019 & -97.952 & $-1.69857 \cdot 10^{-2}$ & $5.38747 \cdot 10^{-2}$ & $8.79161 .10^{-1}$ \\
\hline$(125,0)$ & 105.66 & -101.33 & $-1.19074 .10^{-2}$ & $5.57361 .10^{-2}$ & $9.79797 .10^{-1}$ \\
\hline
\end{tabular}

Thus, when the hole in the middle of plate $C(125,0)$, all the absolute values $\mathrm{K}_{I}, \mathrm{~K}_{I I}$, $J$ become more while the values of COD and $U x$ are less than case, when the hole is sited in the left lower corner of the plate.

\subsubsection{The influence of the crack point position}

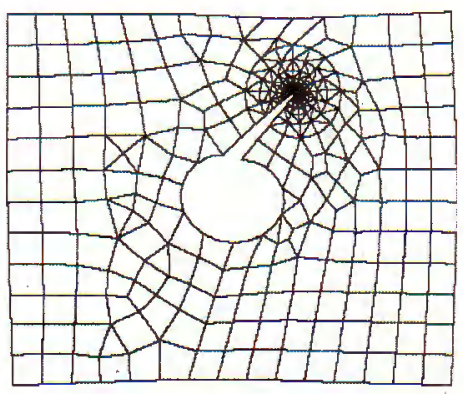

Fig. 5a. The crack shape on the hole in the middle plate, $\mathrm{P} 11(125,25)$

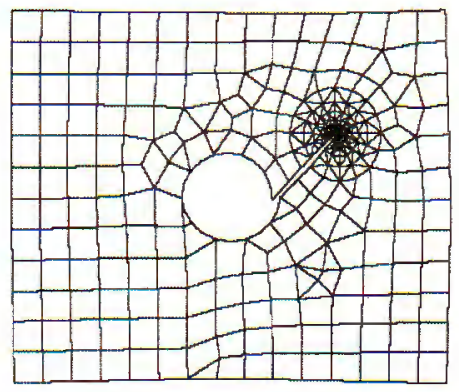

Fig. $5 b$. The crack shape on the hole in the middle plate, $\mathrm{P} 11(150,0)$

Consider the plate with the hole of radius $R=25$ in the middle. Two positions of crack point $P 11$ are investigated: the highest position (in direction $y$ ): $P 11(125,25)$ and lower position $P 11(150,0)$. The results are shown in the Table 7, Fig. 5a and Fig. 5b. 
Table 8. The crack characteristics for the crack at hole in the plate with different position of $P 11$

\begin{tabular}{|c|c|c|c|c|}
\hline $\begin{array}{c}\mathrm{P} 11(\mathrm{x}, \mathrm{y}) \\
(\mathrm{mm})\end{array}$ & $\mathrm{K}_{I}$ & $\mathrm{~K}_{I I}$ & $\begin{array}{c}\text { COD } \\
(\mathrm{mm})\end{array}$ & $\begin{array}{c}\mathrm{Ux} \\
(\mathrm{mm})\end{array}$ \\
\hline$(125,25)$ & 90.372 & -92.990 & $-1.30421 .10^{-2}$ & $6.19066 .10^{-2}$ \\
\hline$(150,0)$ & 62.826 & -69.336 & $-1.5623 .10^{-2}$ & $8.47052 .10^{-2}$ \\
\hline
\end{tabular}

Thus, the position of crack point on the hole has also noticeable influence on the values $\mathrm{K}_{I}, \mathrm{~K}_{I I}$, COD and the crack shape. So, the program RUPHOL can be used to investigate the plate with crack at hole for many different sizes and positions of the hole.

\subsection{Numerical fracture analysis of a gravity dam under self-weight and hy- draulic loading}

With the aim of checking the program, the fracture calculation by RUPDAM is realized for the experimental test 2D model in [5]. In that model the geometric scale between prototype and model was taken to be 40 . The model has a horizontal notch on the upstream side at a quarter of the dam height; with a notch depth is $20 \mathrm{~cm}$ (Fig. 6a). The hydraulic load was modeled by the force $1000 \mathrm{KN}$, which was distributed into concentrated load at all points in the upstream side.

In the case the material has linear behavior with Young's Modulus $E=35.700 \mathrm{MPa}$ the following cases are calculated:

- When external loads are hydraulic loads $1000 \mathrm{KN}$ without self-weight: The calculated Crack Opening Displacement is COD(calcul.) $=0.0449 \mathrm{~mm}$, while the test result COD (test) $\cong 0.055 \mathrm{~mm}$, so RUPDAM gives a acceptable error and the crack shape is shown in Fig. $6 \mathrm{~b}$. The calculated Stress Intensity Factors $\mathrm{K}_{I}=0.703596 \mathrm{MPA} \mathrm{mm}^{0.5}, \mathrm{~K}_{I I}=0.055930$ MPA.mm $m^{0.5}$.

- When external loads are hydraulic with self-weight, the calculated values COD = $0.030638 \mathrm{~mm}, \mathrm{~K}_{I}=0.500374 \mathrm{MPA} . \mathrm{mm}^{0.5}, \mathrm{~K}_{I I}=0.062564 \mathrm{MPA} \mathrm{mm}^{0.5}$. Note that these values are smaller than the values in the case without self-weight and it is reasonable.

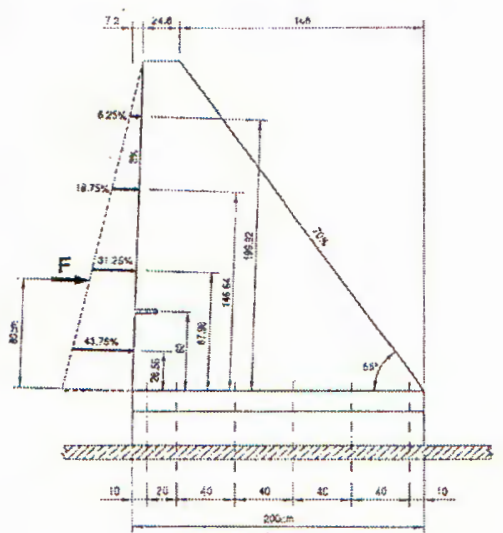

Fig. 6a. The scheme of the testing

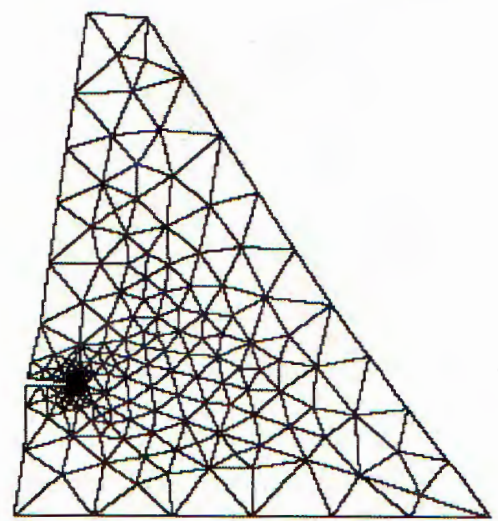

Fig. 6b. The calculated deformation of the crack dam 


\section{CONCLUSION}

In this work, the numerical simulation for crack plates with complicated geometry under different loads is realized successfully. The crack characteristics as COD, Stress Intensity Factors, $J$-integral or the energy release rate $G$ are received for a plates with a centered, inclined crack under uniaxial and biaxial loading and for crack at arbitrary hole in the plate. The 2D model of crack gravity dam under hydrostatic loading and self-weight is also considered. The influence of the plate size or crack size, of the crack point position at hole on the crack characteristics is investigated.

The developed programs based on the Castem 2000 are checked, and compared with analytical or testing results, they give a good agreement, and can be applied to other practical structures.

This work is completed with the partly financial support from the Vietnam National Council of Natural Sciences.

\section{REFERENCES}

1. C. E. A/ D. M. T/L. A. M. S., Castem 2000 Recueil D'exemples Commentes, 1992.

2. Michel Prrat, Philippe Bisch, Alain Millard vv.., Calcul des Ouvrages Generaux de Construction, AFPC- Emploi des elements finis engineer civil, Hermes, Paris, 1997.

3. T. L. Anderson, Fracture Mechanics. Fundamentals and Applications, CRC Press. Boca Raton Ann Arborv London Tokyo, 1992.

4. Stanley T. Rolfe, John M. Barsom, Fracture and Fatigue Control in Structures. Application of Fracture Mechanics, Prentice- Hall, Inc., Englewood Cliffs, New Jersey, 1979.

5. Alberto Capinteri and Silvio Valente and others. Expremental and numerical fracture modelling of a gravity dam. Proceeding of the First International Conference on Fracture Mechanics of Concrete Structures (FraMCoS1), Colorado, USA, 1992 Elsevier Applied Science.

Received October 8, 2005

Revised February 20, 2006

\section{TÍNH TOÁN CÁC THÔNG SỐ CƯA CƠ HỌC PHÁ HUỶ BẰNG PPPTHH CHO MỘT SỐ BÀN NƯT CHỊU CÁC DẠNG TẢI KHẢC NHAU}

Bài báo đã phân tích các bài toán bản có vết nứt bằng phương pháp phần tử hữu hạn. Cơ sở tính toán các thông số đặc trưng vết nứt đã dược trình bày. Một số chương trình đã được thiết lập trên cơ sở phát triển, sử dụng các mođuyn và toán tử của Castem 2000 , kết quả số được kiểm chứng với nghiệm giải tích thể hiện độ tin cậy của chương trình. Ảnh hưởng của kích thước bản, dộ dài vết nứt, vị trí vết nứt, dạng tải trọng đến các thông số SIF, J, G, COD vv đã được xem xét. Các bài toán bản có vết nứt nghiêng, bản có vết nứt tại lỗ hổng, mặt cắt đập có vết nứt chịu tải thuỷ tĩnh đã được phân tích. Kết quả nghiên cứu và các chương trìnł nhận được cho khả năng ứng dụng trong đánh giá phá huỷ công trình bê tông. 